\title{
Biobased aldehydes from fatty epoxides through thermal cleavage of $\beta$-hydroxy hydroperoxides
}

\author{
Thomas De Dios Miguel, [a] Nam Duc Vu, ${ }^{[a]}$ Marc Lemaire, ${ }^{\text {[a] }}$ and Nicolas Duguet ${ }^{*}[a]$
}

[a] T. De Dios Miguel, Dr N. D. Vu, Pr M. Lemaire, Dr N. Duguet

Univ Lyon, Université Claude Bernard Lyon 1, CNRS, INSA-Lyon, CPE-Lyon, Institut de Chimie et Biochimie Moléculaires et Supramoléculaires, ICBMS, UMR 5246, Equipe CAtalyse, SYnthèse et ENvironnement (CASYEN), Bâtiment Lederer, 1 rue Victor Grignard, F-69100 Villeurbanne, France E-mail: nicolas.duguet@univ-lyon1.fr

Supporting information for this article is given in a separate file.

\begin{abstract}
The ring-opening of epoxidized methyl oleate by aqueous $\mathrm{H}_{2} \mathrm{O}_{2}$ has been studied using tungsten and molybdenum catalysts to form the corresponding fatty $\beta$-hydroxy hydroperoxides. It was found that tungstic acid and phosphostungstic acid gave the highest selectivities (92-93\%) towards the formation of the desired products, thus limiting the formation of the corresponding fatty 1,2-diols. The optimized conditions were applied to a range of fatty epoxides to give the corresponding fatty $\beta$-hydroxy hydroperoxides with $30-80 \%$ isolated yields (8 examples). These species were fully characterized by ${ }^{1} \mathrm{H}$ and ${ }^{13} \mathrm{C}$ NMR, HPLC-HRMS and their stability was studied by DSC. The thermal cleavage of the $\beta$-hydroxy hydroperoxide derived from methyl oleate was studied both in batch and flow conditions. It was found that the thermal cleavage in flow conditions gave the highest selectivity towards the formation of aldehydes with limited amounts of byproducts. The aldehydes were both formed with $68 \%$ GC yield and nonanal and methyl 9-oxononanoate were isolated with 57 and $55 \%$ yield, respectively. Advantageously, the overall process does not require large excess of $\mathrm{H}_{2} \mathrm{O}_{2}$ and only generates water as a byproduct.
\end{abstract}

\section{Introduction}

Aldehydes are ubiquitous in organic chemistry as they serve as platform towards other organic functions such as alcohols, carboxylic acids, acetals, imines, amines, and many others. ${ }^{[1]}$ For several years now, the production of bio-based buildingblocks from biomass as a renewable feedstock has become the subject of very intense research. ${ }^{[2]}$ Contrary to carboxylic acids, only a few bio-based aldehydes are readily accessible from renewable resources. On the one hand, furanic aldehydes such as furfural, ${ }^{[3]}$ 5-hydroxymethyl furfural $(5-\mathrm{HMF})^{[4]}$ and 2,5diformylfuran ${ }^{[5]}$ can be obtained from lignocellulosic biomass. In addition, other aromatic aldehydes such as vanillin and its derivatives can be produced from lignin. ${ }^{[6]}$ On the other hand, vegetable oils are interesting renewable resources ${ }^{[7]}$ to prepare aliphatic aldehydes. ${ }^{[8]}$

Hydroformylation of unsaturated vegetable oils and their fatty acid derivatives can give access to the corresponding homologated branched aldehydes. ${ }^{\left[{ }^{[]}\right.}$However, despite its high atom-economy and feasibility at the industrial scale, hydroformylation involves the use carbon monoxide and hydrogen, thus requiring specialized high-pressure equipments. Complementarily, the cleavage of unsaturated fatty acid derivatives can produce aliphatic linear aldehydes. These aldehydes are of prime importance since they can used to prepare $100 \%$ bio-based surfactants by reductive etherification of polyols and sugar derivatives. ${ }^{[10]}$ In addition, functionalized aldehydes can be transformed to monomers for the preparation of polyesters and polyamides through reduction or reductive amination, respectively. ${ }^{[11]}$ The cleavage of fatty acid derivatives is usually carried out in the presence of strong oxidants (i.e., oxidative cleavage)..$^{[12]}$ This means that fatty aldehydes are difficult to obtain selectively through these methods since they are readily oxidized to carboxylic acids under these conditions. In this context, other strategies should be employed.

The cleavage of fatty epoxides or 1,2-diols to aldehydes was traditionally be carried out using $\mathrm{HIO}_{4}$ or $\mathrm{NalO}_{4}$, respectively. ${ }^{[13]}$ However, the use of these stoichiometric oxidants leads to the generation of large quantities of waste that could not be valorized. One of the most efficient, clean and general method to produce fatty aldehydes is reductive ozonolysis. ${ }^{[14]}$ In that case, unsaturated fatty acids are over-oxidized with ozone to give the corresponding ozonides. These reactive intermediates are then reduced - typically using zinc, dimethylsulfide, triphenylphosphine or hydrogen - to aldehydes, thus limiting the formation of carboxylic acids as contaminants. Reductive ozonolysis is very attractive from an atom-economy point of view but suffers from the use of ozone that is extremely toxic for both humans and environment. Moreover, ozonolysis is a very energy-intensive process as ozone is produced from oxygen using an electric discharge. Recently, our group has reported an alternative approach consisting in the catalytic cleavage of fatty $\alpha$-hydroxyketones to aldehydes under non- oxidative conditions. First, $\alpha$-hydroxyketones were prepared by selective catalytic oxidation or dehydrogenation of fatty 1,2-diols. ${ }^{[15]}$ Then, these intermediates were organocatalytically cleaved by retro-benzoin condensation in the presence of thiazoliums salts to give the corresponding aldehydes. ${ }^{[16]}$ Albeit that this catalytic route could be attractive, it has not been demonstrated on a large scale yet. Finally, it was shown that ricinoleic derivatives, obtained from castor oil, can be thermally cleaved at high temperature (typically $>300^{\circ} \mathrm{C}$ ) to give bio-based heptanal and undecylenic acid through a retro-ene reaction. ${ }^{[17]}$ Noteworthy, this process is carried out on the industrial scale since undecylenic acid can be further converted to 11-aminoundecanoic acid, which is the precursor of nylon-11 (Rilsan $\AA$ ). Despite that this cleavage process is specific to ricinoleic derivatives and could not been applied to other fatty acid derivatives, it clearly demonstrates that the thermal cleavage of vegetable oil derivatives can be an economically-viable route. However, so far, the thermal 
cleavage of other fatty acid derivatives has been largely underexploited. Recently, the cleavage of fatty epoxides to aldehydes has been claimed to be feasible using $\mathrm{H}_{2} \mathrm{O}_{2}$ as an oxidant in the presence of $\mathrm{WO}_{3},{ }^{[18]} \mathrm{WO}_{3} / \mathrm{MCM}-41,{ }^{[19]}$ and $\mathrm{H}_{2} \mathrm{WO}_{4} @ \mathrm{Al}-\mathrm{MCM}-41,{ }^{[20]}$ even at room temperature. However, in these studies, the authors have only reported GC yields and no aldehydes were isolated. ${ }^{[21]}$ In sharp contrast, in the present work, we demonstrate that these reported conditions do not lead to the formation of aldehydes but only produce $\beta$-hydroxy hydroperoxide species as reaction intermediates (vide infra).

In this context, we now report here the preparation, the isolation and the characterisation (including DSC) of fatty $\beta$-hydroxy hydroperoxides prepared from epoxides. Moreover, we also report their thermal cleavage into fatty aldehydes in batch and in flow (Scheme 1). ${ }^{[22]}$

$$
\underset{7 \text { (cat.) }}{\substack{\mathrm{H}_{2} \mathrm{O}_{2} \\ \text { (cat) }}}
$$

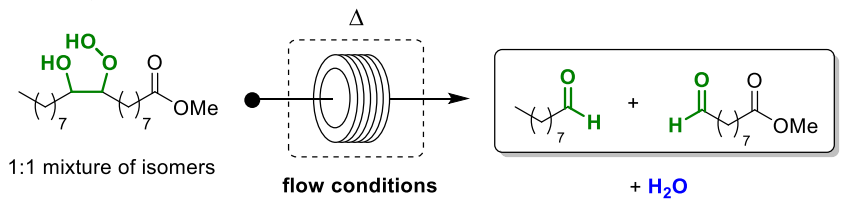

Scheme 1. Cleavage of fatty epoxides to aldehydes through $\beta$-hydroxy hydoperoxides.

\section{Results and Discussion}

\section{Preparation of fatty $\beta$-hydroxy hydroperoxides}

The chemistry of $\beta$-hydroxy hydroperoxides is relatively unexplored. ${ }^{[23]}$ These species are usually prepared by ringopening of epoxides with $\mathrm{H}_{2} \mathrm{O}_{2} \cdot{ }^{[24]}$ Early works used Brönsted acids as catalysts such as $\mathrm{HClO}_{4}{ }^{[25]}$ and $\mathrm{CF}_{3} \mathrm{CO}_{2} \mathrm{H}_{.}{ }^{[26]}$ Moreover, Lewis acids such as $\mathrm{SnCl}_{4},{ }^{[27]} \quad \mathrm{SbCl}_{3} / \mathrm{SiO}_{2}{ }^{[28]}$ and phosphomolybdic acid ${ }^{[29]}$ (PMA) were also used to promote the reaction. Recently, magnetic nanoparticules-supported phosphomolybdate ${ }^{[30]}$ and nano-graphene oxide-supported molybdenum ${ }^{[31]}$ were reported as recoverable and recyclable catalysts. Despite that these methods provide $\beta$-hydroxy hydroperoxides with high yields, they require the use of neat or ethereal $\mathrm{H}_{2} \mathrm{O}_{2}$. In sharp contrast with other oxidized fatty derivatives, fatty $\beta$-hydroxy hydroperoxides has been scarcely reported. To the best of our knowledge, the first synthesis of an oleochemical $\beta$-hydroxy hydroperoxide was reported by Hiroko et al. in a patent. ${ }^{[32]}$ In this work, methyl oleate was treated with 5 equivalents of aqueous $30 \% \mathrm{H}_{2} \mathrm{O}_{2}$ at $35^{\circ} \mathrm{C}$, in the presence of tungstic acid. Under these conditions, the corresponding $\beta$ hydroxy hydroperoxides was obtained with only $28 \%$ yield. Similarly, Ruffo et al. have reported the direct oxidation of oleic acid using an excess of $30 \% \mathrm{H}_{2} \mathrm{O}_{2}$ (4 equiv.) in the presence of tungstic acid. ${ }^{[3]}$ After 4 hours at $70^{\circ} \mathrm{C}$, the desired $\beta$-hydroxy hydroperoxide was obtained with only $45 \%$, mainly due to the formation (45\% NMR yield) of the corresponding 1,2-diol as a by-product. Overall, these two works show that the direct oxidation of oleic acid derivatives is giving fatty $\beta$-hydroxy hydroperoxides with low yields. This is probably due to the use of a large excess of $\mathrm{H}_{2} \mathrm{O}_{2}$, resulting in the production of many by-products.

In this context, we have first investigated the preparation of fatty $\beta$-hydroxy hydroperoxides by ring-opening of epoxidized methyl oleate using a $35 \%$ aqueous solution of $\mathrm{H}_{2} \mathrm{O}_{2}$. Several parameters were screened such as the nature of the catalyst, the catalyst loading, the concentration of starting material and the temperature. However, despite a full conversion of the starting material, the selectivity did not reach more than $80 \%$ due to the formation of the corresponding 1,2-diol. This diol is formed by ring-opening of the epoxide with water, that is a competing nucleophile for hydrogen peroxide. Therefore, in order to limit the formation of this diol, a $50 \%$ aqueous solution of $\mathrm{H}_{2} \mathrm{O}_{2}$ was used for further optimization. ${ }^{[34]} \mathrm{A}$ range of catalysts was first screened for the ring-opening of epoxidized methyl oleate 1 using aq. $50 \% \mathrm{H}_{2} \mathrm{O}_{2}$ (Table 1 ).

Table 1. Optimization for the preparation of fatty $\beta$-hydroxy hydroperoxides by ring-opening of epoxidized methyl oleate with $\mathrm{H}_{2} \mathrm{O}_{2}$. ${ }^{\text {[a] }}$

\begin{tabular}{|c|c|c|c|c|c|}
\hline$Y_{7}$ & ${ }_{7}^{\mathrm{O}}$ & 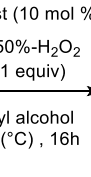 & 1:1 mixture of & Ders & ${ }_{3} \mathrm{H}_{7}$ \\
\hline Entry & $\begin{array}{l}\text { Cat. } \\
\text { (loading, } \\
\text { mol\%) }\end{array}$ & $\begin{array}{l}\text { Temp. } \\
\left({ }^{\circ} \mathrm{C}\right)\end{array}$ & $\begin{array}{l}\text { Conv. } .^{[b]} 1 \\
(\%)\end{array}$ & $\begin{array}{l}\text { Ratio }^{[b]} \mathbf{2} \\
(\%)\end{array}$ & $\begin{array}{l}\text { Ratio }^{[b]} 3 \\
(\%)\end{array}$ \\
\hline 1 & $\mathrm{MoO}_{4}(10)$ & 20 & 16 & 11 & 5 \\
\hline 2 & $\mathrm{WO}_{3}(10)$ & 20 & 6 & 6 & 0 \\
\hline 3 & PMA (10) & 20 & $>99$ & 85 & 15 \\
\hline 4 & $\mathrm{H}_{2} \mathrm{WO}_{4}(10)$ & 20 & $>99$ & 93 & 7 \\
\hline 5 & PTA (10) & 20 & $>99$ & 20 & 66 \\
\hline 6 & PTA (1) & 20 & $>99$ & 80 & 20 \\
\hline 7 & PTA (0.1) & 20 & $>99$ & 90 & 10 \\
\hline 8 & PTA (0.1) & 10 & $>99$ & 92 & 8 \\
\hline 9 & PTA (0.1) & 5 & 67 & 61 & 6 \\
\hline 10 & PTA $(0.1)$ & 0 & 50 & 44 & 6 \\
\hline 11 & - & 10 & 6 & 3 & 3 \\
\hline
\end{tabular}

[a] Reaction conditions: epoxide $1(1.00 \mathrm{~g}, 2.90 \mathrm{mmol})$, aq. $50 \%-\mathrm{H}_{2} \mathrm{O}_{2}(0.22$ $\mathrm{mL}, 3.18 \mathrm{mmol}, 1.1$ equiv), catalyst (0.1-10 mol\%), tert-amyl alcohol (12 mL), $20^{\circ} \mathrm{C}, 16$ hours. [b] Conversion and ratio were determined by HPLC. PMA: phosphomolybdic acid $\left(\mathrm{H}_{3} \mathrm{PO}_{4} .12 \mathrm{MoO}_{3}\right)$, PTA: phosphotungstic acid $\left(\mathrm{H}_{3} \mathrm{PO}_{4} .12 \mathrm{WO}_{3}\right)$.

The reaction was performed in tert-amyl alcohol at $20^{\circ} \mathrm{C}$ for 16 hours. Molybdenum and tungsten oxides were first tested but they gave poor results (Table 1, entries 1-2). The use of phosphosmolybdic acid (PMA) allows to reach full conversion and the desired peroxide 2 was obtained with $85 \%$ selectivity (Table 1, entry 3). A slightly better selectivity (93\%) was obtained with tungstic acid (Table 1, entry 4). Surprisingly, phosphotungstic acid (PTA) only give $20 \%$ of 2 and the corresponding 1,2-diol was obtained as the major product with $66 \%$ HPLC ratio (Table 1, entry 5). However, by decreasing the 
catalyst loading from 10 to $0.1 \mathrm{~mol} \%$, the selectivity towards 2 can be improved until 90\% (Table 1, entries 6-7). Moreover, a selectivity of $92 \%$ can be reached by decreasing the temperature to $10^{\circ} \mathrm{C}$ (Table 1, entry 8). However, no further improvement can be achieved by decreasing the temperature to 5 or $0^{\circ} \mathrm{C}$ (Table 1 , entries $9-10$ ). Finally, a blank experiment was carried out without catalyst under the optimized conditions. Under these conditions, the conversion of 1 reached $6 \%$ and only $3 \%$ of peroxide 2 was formed (Table 1, entry 11). This result demonstrates the crucial role of PTA to activate $\mathrm{H}_{2} \mathrm{O}_{2}$, as recently reported in a patent. ${ }^{[35]}$

From our results, it is striking to see that only $\beta$-hydroxy hydroperoxides were produced and no aldehydes were obtained, in sharp contrast with reported studies carried out under similar conditions. ${ }^{[18-20]}$ In order understand these differences, we have reproduced the conditions previously described in the literature with unsupported $\mathrm{WO}_{3}$ and $\mathrm{H}_{2} \mathrm{WO}_{4}$ (Table 2).

Table 2. Reproduction of previously reported conditions.

\begin{tabular}{|c|c|c|c|c|c|}
\hline 1 & $\begin{array}{r}\text { Cate } \\
a \\
(1 \\
\end{array}$ & $\begin{array}{l}\text { st }(1.7 \mathrm{~mol} \\
30 \%-\mathrm{H}_{2} \mathrm{O}_{2} \\
-1.3 \text { equiv) } \\
\text { onditions }\end{array}$ & 1:1 mixture of & vers & $\mathrm{X}_{3} \mathrm{H}_{7}$ \\
\hline Entry & $\begin{array}{l}\text { Cat. } \\
\text { (loading, } \\
\text { mol\%) }\end{array}$ & $\begin{array}{l}\text { Temp. } \\
\left({ }^{\circ} \mathrm{C}\right)\end{array}$ & $\begin{array}{l}\text { Conv. }{ }^{[\mathrm{d}]} \mathbf{1} \\
(\%)\end{array}$ & $\begin{array}{l}\text { Ratio }^{[\mathrm{d}]} \mathbf{2} \\
\text { (\%) }\end{array}$ & $\begin{array}{l}\text { Ratio }^{[\mathrm{dd}]} \mathbf{3} \\
(\%)\end{array}$ \\
\hline $1^{[a]}$ & $\mathrm{WO}_{3}(1.7)$ & 70 & 4 & 3 & 1 \\
\hline $2^{\mathrm{b}]}$ & $\mathrm{WO}_{3}(1.7)$ & 25 & 90 & 70 & 20 \\
\hline $3^{[c]}$ & $\mathrm{H}_{2} \mathrm{WO}_{4}(1.7)$ & 25 & $>99$ & 85 & 14 \\
\hline
\end{tabular}

[a] Conditions taken from ref. 18: epoxide $1(1.56 \mathrm{~g}, 5 \mathrm{mmol})$, aq. $30 \%-\mathrm{H}_{2} \mathrm{O}_{2}$ (6.5 mmol, 1.3 equiv), $\mathrm{WO}_{3}(0.085 \mathrm{mmol}, 1.7 \mathrm{~mol} \%)$, neat, $70^{\circ} \mathrm{C}, 20 \mathrm{~min}[\mathrm{~b}]$ Conditions taken from ref. 20: epoxide $1(3.12 \mathrm{~g}, 10 \mathrm{mmol})$, aq. $30 \%-\mathrm{H}_{2} \mathrm{O}_{2}(12$ mmol, 1.2 equiv), $\mathrm{WO}_{3}(0.17 \mathrm{mmol}, 1.7 \mathrm{~mol} \%)$, tert-butanol $(5 \mathrm{~mL}), 25^{\circ} \mathrm{C}, 18 \mathrm{~h}$ [c] Conditions taken from ref. 20: epoxide $1(3.12 \mathrm{~g}, 10 \mathrm{mmol})$, aq. $30 \%-\mathrm{H}_{2} \mathrm{O}_{2}$ (12 mmol, 1.2 equiv), $\mathrm{H}_{2} \mathrm{WO}_{4}(0.17 \mathrm{mmol}, 1.7 \mathrm{~mol} \%)$, tert-butanol $(5 \mathrm{~mL})$, $25^{\circ} \mathrm{C}, 2 \mathrm{~h}$. [d] Conversion and ratio were determined by HPLC.

Using $\mathrm{WO}_{3}$ at $70^{\circ} \mathrm{C}$ for $20 \mathrm{~min}$ under neat conditions, ${ }^{[18]}$ the conversion of 1 was only $4 \%$ and $\beta$-hydroxy hydroperoxide 2 was obtained with $3 \%$ HPLC ratio (Table 2, entry 1). Using either $\mathrm{WO}_{3}$ or $\mathrm{H}_{2} \mathrm{WO}_{4}$ at room temperature $\left(25^{\circ} \mathrm{C}\right)$ in tert-butanol[20] led to 90 and $99 \%$ conversion and the HPLC ratio of $\beta$-hydroxy hydroperoxide 2 reached 70 and $85 \%$, respectively (Table 2, entries 2-3). Our results clearly demonstrate that the reported conditions are adequate to form $\beta$-hydroxy hydroperoxides but are completely ineffective for producing aldehydes, contrary to what was previously claimed. ${ }^{[18-20]}$ This is explained by the fact that, in these works, the yield of aldehydes was determined by GC without checking the full conversion of $\beta$-hydroxy hydroperoxide intermediates (e.g., by NMR or HPLC). Therefore it is completely misguiding because we found that $\beta$-hydroxy hydroperoxides readily decomposed in the GC injector to form the desired aldehydes during the analysis (vide infra).

Then, the scope for the ring-opening of epoxides with $\mathrm{H}_{2} \mathrm{O}_{2}$ was next investigated with a range of fatty epoxides under our optimized conditions (Figure 1).
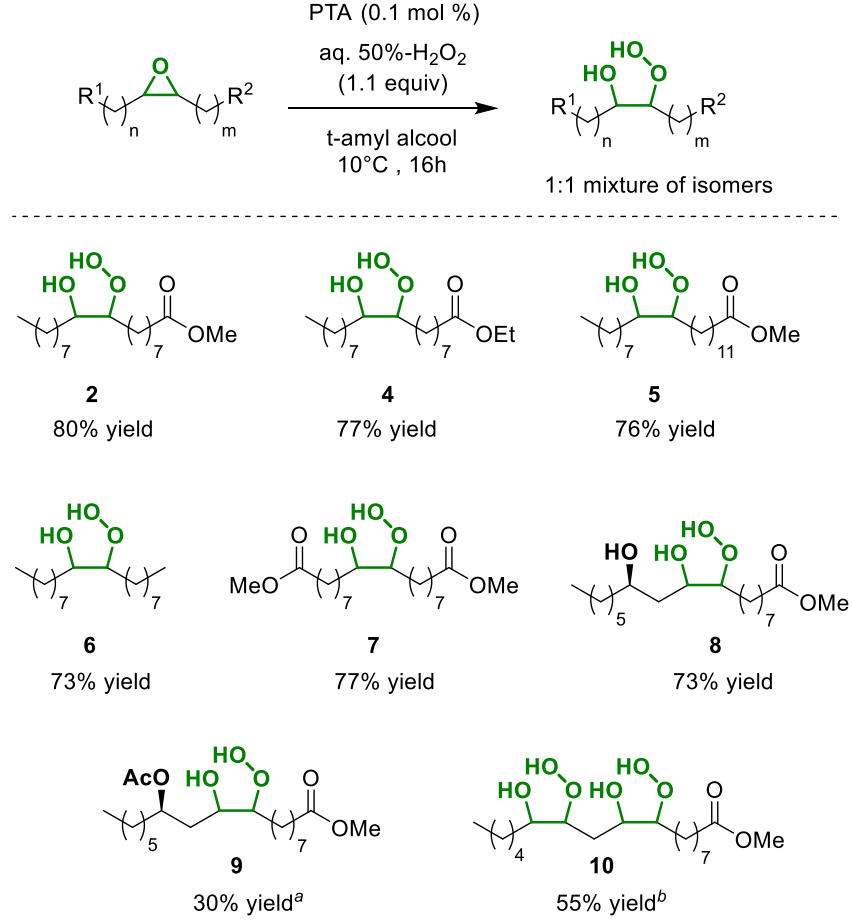

Figure 1. Scope for the formation of fatty $\beta$-hydroxy hydroperoxides. [a] The corresponding 1,2-diol was recovered as the main product. ${ }^{[b]} 0.2 \mathrm{~mol} \%$ of PTA was used ( $0.1 \mathrm{~mol} \%$ by epoxide function) and 2.2 equiv of $50 \%-\mathrm{H}_{2} \mathrm{O}_{2}$.

Epoxidized methyl oleate 1 gave the corresponding $\beta$-hydroxy hydroperoxide 2 with $80 \%$ isolated yield after purification by column chromatography. This demonstrates that fatty $\beta$-hydroxy hydroperoxides are quite robust species and are not sensitive to slightly acidic conditions such as silica. Compound $\mathbf{2}$ was first characterized by NMR. In the ${ }^{1} \mathrm{H}$ NMR spectrum, the chemical shifts at 11.2 and $4.3 \mathrm{ppm}$ are characteristic signals for $-\mathrm{OOH}$ and $-\mathrm{OH}$ groups, respectively (Figure 2).

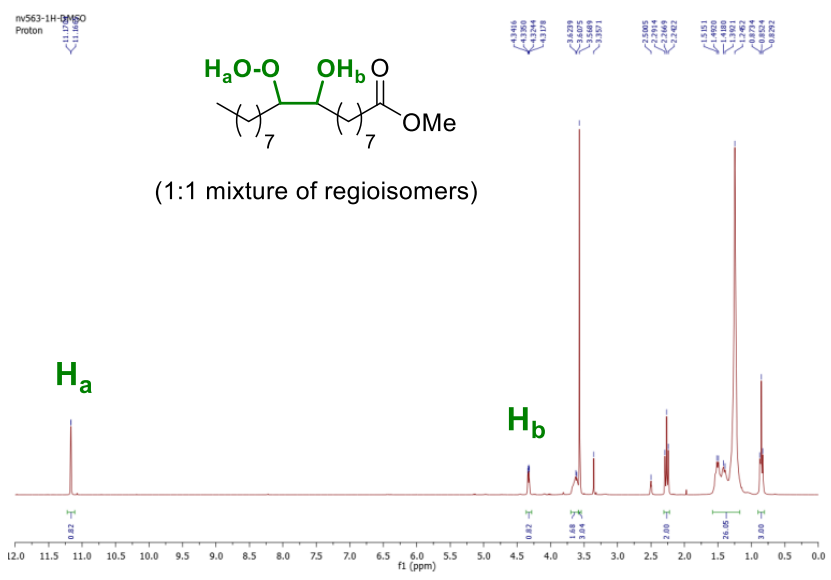

Figure 2. ${ }^{1} \mathrm{H}-\mathrm{NMR}$ spectrum $\left(300 \mathrm{MHz}\right.$, DMSO- $\left.d_{6}\right)$ of $\beta$-hydroxy hydroperoxide 2.

Moreover, two signals at 69 and $87 \mathrm{ppm}$ in ${ }^{13} \mathrm{C}$ NMR clearly indicate the presence of the two $\mathrm{CH}$ of the $\beta$-hydroxy hydroperoxide function (see spectrum in ESI). Finally, the mass 
of 2 was also confirmed by HPLC-HRMS (see ESI). Then, ethyl oleate was also considered and it gave the corresponding $\beta$ hydroxy hydroperoxides 4 with $77 \%$ isolated yield. Similarly, hydroperoxide 5, obtained from epoxidized methyl erucate, was obtained with $76 \%$ isolated yield. It should be noted that products 2, 4-5 were obtained as a 50:50 mixture of regioisomers. The fatty epoxides derived from the selfmetathesis products of methyl oleate were also used as starting materials and the corresponding $\beta$-hydroxy hydroperoxides 6 and 7 were isolated with $73 \%$ and $77 \%$ yield, respectively. For methyl ricinolate derivatives, very contrasting results were obtained: hydroperoxide 8 was obtained with $73 \%$ yield starting from epoxidized methyl ricinoleate (i.e. with unprotected alcohol at the position 12), while its $O$-acyl-protected analogue only gave hydroperoxide 9 with $30 \%$ yield. In that case, the corresponding 1,2-diol was formed as the major compound. The presence of the 12-OAc group may bring enough steric hindrance to prevent the addition of $\mathrm{H}_{2} \mathrm{O}_{2}$ and thus favour the nucleophilic addition of water. Finally, the bis-epoxide prepared from methyl linoleate was also subjected to the ring-opening with $\mathrm{H}_{2} \mathrm{O}_{2}$ and the corresponding bis-( $\beta$-hydroxy hydroperoxide) 10 was isolated with $55 \%$ yield. Interestingly, the product is a mixture of 8 isomers (as observed by ${ }^{1} \mathrm{H}$ NMR) resulting from unselective nucleophilic addition of $\mathrm{H}_{2} \mathrm{O}_{2}$ to a mixture of cis-cis and cis-trans epoxides. However, this lack of selectivity is not a problem considering that all isomers will be thermally cleaved to give the corresponding aldehydes.

\section{Thermal cleavage of fatty $\beta$-hydroxy hydroperoxides}

The cleavage of $\beta$-hydroxy hydroperoxides has been scarcely reported in the literature. Early works showed that these species could undergo acid-[36] or base-catalyzed ${ }^{[37]}$ decomposition to give a variety of carbonyl compounds. More recently, Salomon et al. have investigated the fragmentation of hydroperoxide species in water under physiological conditions. ${ }^{[38]}$ The authors have shown that the combination of vitamin $C$ and metal cations such as $\mathrm{Fe}^{3+}$ and $\mathrm{Cu}^{2+}$ could give aldehydes - as hydrated form - with up to $66 \%$ yield. While studying the oxidative cleavage of olefins to carboxylic acids, Venturello et al. have also shown that an aliphatic $\beta$-hydroxy hydroperoxide could decompose at $85^{\circ} \mathrm{C}$ in the presence of a quaternary ammonium dioxoperotungstate. ${ }^{[39]}$ In that case, the conversion reached $63 \%$ and the selectivity towards aldehydes was only $62 \%$ due to the formation of the corresponding acids (11\%), $\alpha$-hydroxyketone $(14 \%)$ and 1,2-diol (8\%) as byproducts. During the characterization of $\beta$-hydroxy hydroperoxide $\mathbf{2}$ by gas chromatography, we observed that the compound was not detected on the GC chromatogram, suggesting that it was completely degraded. ${ }^{[22]}$ However, the chromatogram was clean with 2 major peaks, that were assigned to nonanal 11 and methyl 9-oxononanoate (methyl azelaaldehydate) 12 (Figure 3). A minor product was also detected and was assigned to the corresponding $\alpha$-hydroxyketone 13 . This demonstrates that hydroperoxide $\mathbf{2}$ was totally converted in the GC injector (set at $300^{\circ} \mathrm{C}$ ) to give the corresponding aldehydes. Hence, we envisioned that $\beta$-hydroxy hydroperoxide 2 could be selectively cleaved to the corresponding aldehydes by thermal cleavage under catalyst-free conditions. However, hydroperoxides species are known to be energetic compounds that could present safety risks.

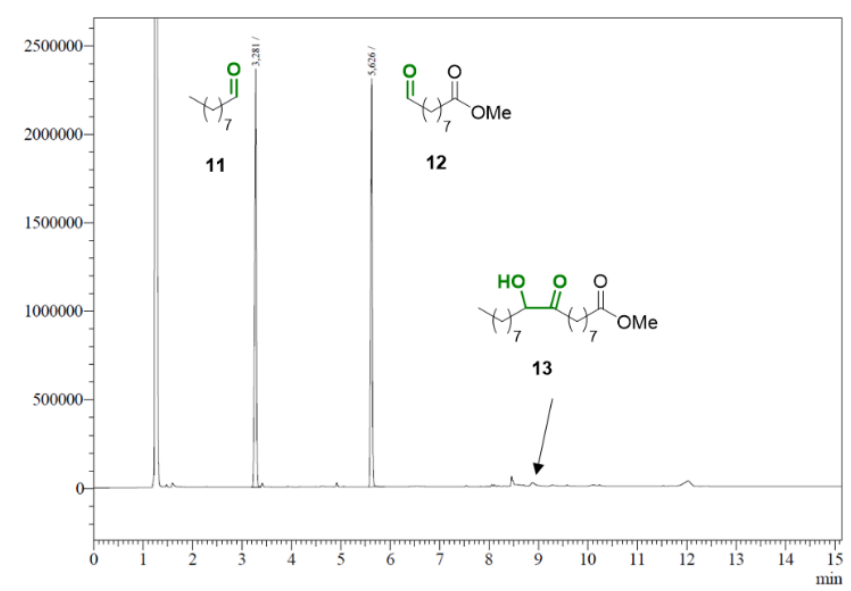

Figure 3. GC Chromatogram of $\beta$-hydroxy hydroperoxide 2 showing its decomposition to aldehydes (injector temperature $=300^{\circ} \mathrm{C}$ ).

That is the reason why the thermal stability of fatty $\beta$-hydroxy hydroperoxide 2 (neat) was first studied by Differential Scanning Calorimetry (Table 3 and ESI).

Table 3. Comparison of decomposition enthalpies of fatty $\beta$-hydroxy hydroperoxides and ozonides. ${ }^{[a]}$

\begin{tabular}{|c|c|c|c|c|c|}
\hline \multirow[t]{2}{*}{ Entry } & \multirow[t]{2}{*}{ Fatty compound } & \multirow[t]{2}{*}{$\begin{array}{l}\mathrm{MW} \\
(\mathrm{g} / \mathrm{mol})\end{array}$} & \multicolumn{2}{|c|}{$\begin{array}{l}\text { DSC decomposition } \\
\text { enthalpy }\end{array}$} & \multirow[t]{2}{*}{$\mathrm{T}\left({ }^{\circ} \mathrm{C}\right.$} \\
\hline & & & $(\mathrm{J} / \mathrm{g})$ & $(\mathrm{KJ} / \mathrm{mol})$ & \\
\hline 1 & Hydroperoxide 2 & 346.5 & -611 & -211 & 107 \\
\hline 2 & Hydroperoxide 4 & 360.5 & -628 & -226 & 113 \\
\hline $3^{[40]}$ & Ethyl oleate ozonide & 358.5 & -684 & -245 & 156 \\
\hline $4^{[41]}$ & Ethyl oleate ozonide & 358.5 & -742 & -266 & 137 \\
\hline $5^{[41]}$ & Ethyl elaidate ozonide & 358.5 & -737 & -264 & 139 \\
\hline
\end{tabular}

[a] Values obtained from the thermal analysis by DSC.

The thermal analysis shows that compound 2 decomposes with a peak at $107^{\circ} \mathrm{C}$ and the decomposition enthalpy reaches -611 $\mathrm{J} / \mathrm{g}$ (Table 3, entry 1 ). Similar results were obtained with the $\beta$ hydroxy hydroperoxide derived from ethyl oleate (Table 3, entry 2 ). The thermal analysis data for the other fatty $\beta$-hydroxy hydroperoxides is given in the supporting information. By comparison, the DSC analysis of the thermal decomposition of the ozonides prepared from ethyl oleate gives a decomposition enthalpy of $-684 \mathrm{~J} / \mathrm{g}$ and a decomposition temperature of $156^{\circ} \mathrm{C}$, as reported by Cataldo (Table 3, entry 3 ). ${ }^{[40]}$ In another studies, the same author has also shown that the ozonides prepared from either ethyl oleate or ethyl elaidate gave very similar decomposition enthalpies and temperatures (Table 3, entries 45). ${ }^{[41]}$ This preliminary study on the thermal behaviour of fatty $\beta$ hydroxy hydroperoxides shows that these oxygenated species decompose at lower temperature than the corresponding ozonides but release less energy. Interestingly, similarly than fatty ozonides, the shape of the heat decomposition of fatty $\beta$ hydroxy hydroperoxides is very broad, indicating a gradual release of heat. For comparison, the shape of explosive azide 
compounds is usually very sharp and release much more energy (e.g., a heat release of $1770 \mathrm{~kJ} / \mathrm{kg}$ for the Zhdankin reagent, ABX). ${ }^{[42]}$ The cleavage of fatty $\beta$-hydroxy hydroperoxide 2 was first studied in batch conditions (Table 4). The reaction was initially conducted in tert-amylalcohol at $80^{\circ} \mathrm{C}$ (Table 4 , entry 1 ).

Table 4. Optimization for the thermal cleavage of fatty $\beta$-hydroxy hydroperoxide 2 in batch conditions. ${ }^{[a]}$

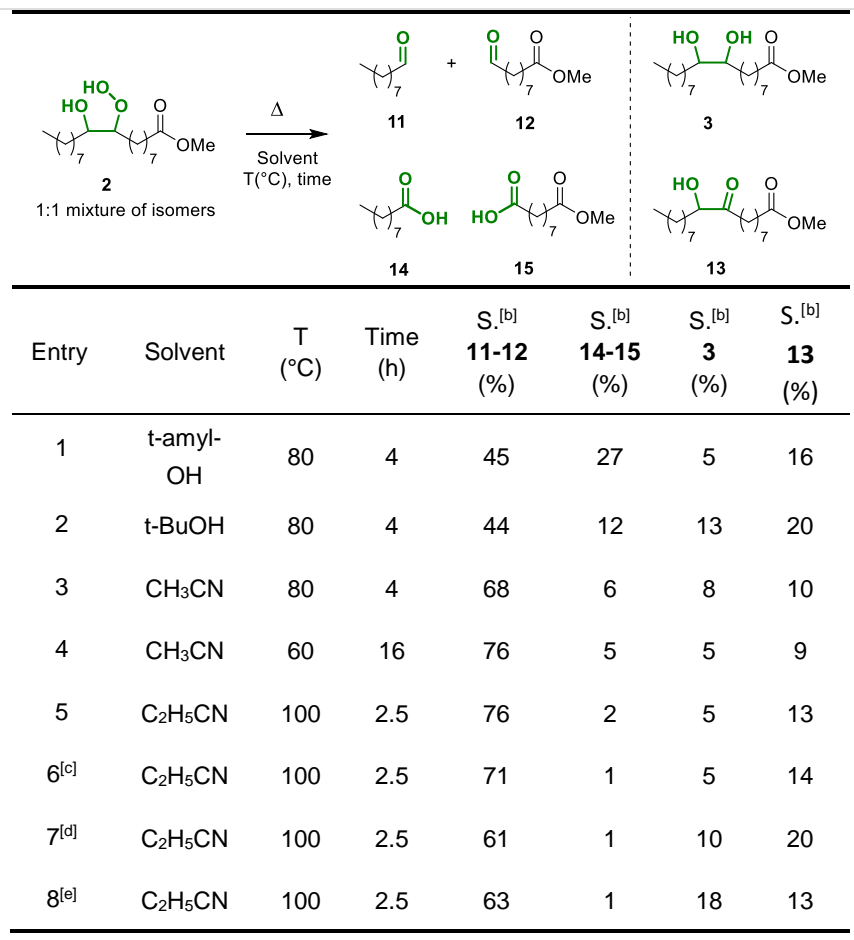

[a] Reaction conditions: $25-\mathrm{mL}$ Schlenk flask, $\beta$-hydroxy hydroperoxide 2 (173 $\mathrm{mg} \mathrm{g}, 0.5 \mathrm{mmol})$, solvent ( $2 \mathrm{~mL}, 0.25 \mathrm{M})$. The conversion of 2 was determined by NMR and was found to be complete in all cases. [b] Selectivities were determined by $\mathrm{GC}$. [c] $\mathrm{CH}_{3} \mathrm{CH}_{2} \mathrm{CN}(4 \mathrm{~mL}, 0.12 \mathrm{M}$ ) was used. [d] the reaction was carried out in the presence of Amberlite-15 (10 wt\%). [e] DBU (10 mol\%) was used.

Under these conditions, the conversion was full after 4 hours. However, the selectivity towards aldehydes 11 and 12 only reached $45 \%$ due to the formation of acids 14 and $15(27 \%)$, 1,2-diol $3(5 \%)$ and $\alpha$-hydroxyketone 13 (16\%). A similar selectivity was obtained in tert-butanol but less acids and more diol were produced (Table 4, entry 2). Satisfyingly, the selectivity towards aldehydes increased to $68 \%$ when the reaction was carried out in acetonitrile (Table 4 , entry 3 ). This selectivity was further increased to $76 \%$ when the reaction was performed at $60^{\circ} \mathrm{C}$, provided a prolonged reaction time (Table 4 , entry 4). More interestingly, similar results could be obtained in propionitrile at $100^{\circ} \mathrm{C}$ in only 2.5 hours (Table 4, entry 5). Other parameters were tested such as the concentration of substrate and the addition of acid or base catalyst (Table 4, entries 6-8). However, no improvement could be obtained under these conditions. In conclusion, the preliminary results obtained for the cleavage of $\beta$-hydroxy hydroperoxide 2 in batch conditions suggest that the selectivity of aldehydes 11-12 could be further improved by increasing the temperature. Therefore, we envisioned that the thermal cleavage could be carried out at higher temperature in a very short time, i.e., working under continuous flow conditions. A solution of 2 in $\mathrm{CH}_{3} \mathrm{CN}(10 \mathrm{~g} / \mathrm{L})$ was first introduced at a flow rate of $2 \mathrm{~mL} / \mathrm{min}$ into an oven at $100^{\circ} \mathrm{C}$ (Table 5). ${ }^{[43]}$ Under these conditions, the conversion only reached $20 \%$, indicating that the reaction temperature was not high enough at this flow rate (Table 5 , entry 1 ). Increasing the temperature from 100 to $300^{\circ} \mathrm{C}$ led to a $90 \%$ conversion (Table 5 , entries 2-3). No attempt has been made to further increase this temperature. Doubling the concentration to $20 \mathrm{~g} / \mathrm{L}$ only led to $54 \%$ conversion (Table 5 , entry 4 ). Increasing the flow rate to 5 or $10 \mathrm{~mL} / \mathrm{min}$ reduced the residence time to 36 and $18 \mathrm{~s}$, respectively, thus leading to a drastic drop of the conversion (Table 5, entries 5-6). On the contrary, decreasing the flow rate to $1 \mathrm{~mL} / \mathrm{min}$ gave a full conversion of $\beta$-hydroxy hydroperoxide 2 (Table 5, entry 7).

Table 5. Optimization for the thermal cleavage of fatty $\beta$-hydroxy hydroperoxide 2 in continuous flow conditions. ${ }^{[a]}$

\begin{tabular}{|c|c|c|c|c|c|c|}
\hline 1:1 mixture & $\begin{array}{l}\text { ON } \\
\text { OMe } \\
\text { Nomers } \\
\text { some }\end{array}$ & $\begin{array}{c}\Delta \\
((-)))) \\
\text { flow mode } \\
T\left({ }^{\circ} \mathrm{C}\right) \text {, time }\end{array}$ & $\begin{array}{r}0 \\
Y Y_{7} \\
11\end{array}$ & $\underbrace{\circ}_{12}$ & $\begin{array}{lll} & 10 \\
& \end{array}$ & 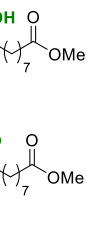 \\
\hline Entry & $\begin{array}{c}\mathrm{T} \\
\left({ }^{\circ} \mathrm{C}\right)\end{array}$ & $\begin{array}{c}\text { Flow } \\
(\mathrm{mL} / \mathrm{min})\end{array}$ & $\begin{array}{c}\text { Residence } \\
\text { time (s) }\end{array}$ & $\begin{array}{c}\text { Conv. } .^{[b]} \\
2(\%)\end{array}$ & $\begin{array}{l}\text { Ratio[c] }^{[c} \\
11 \text { and } \\
12 \text { (\%) }\end{array}$ & $\begin{array}{c}\text { Ratio }^{[c]} \\
3 \text { and } \\
13 \text { (\%) }\end{array}$ \\
\hline 1 & 100 & 2 & 90 & 20 & nd & 20 \\
\hline 2 & 200 & 2 & 90 & 33 & 8 & 9 \\
\hline 3 & 300 & 2 & 90 & 90 & 58 & 22 \\
\hline $4^{[d]}$ & 300 & 2 & 90 & 54 & 14 & 29 \\
\hline 5 & 300 & 5 & 36 & 10 & nd & 10 \\
\hline 6 & 300 & 10 & 18 & 0 & - & - \\
\hline 7 & 300 & 1 & 180 & $>99$ & 81 & 12 \\
\hline
\end{tabular}

[a] Reaction conditions: $\beta$-hydroxy hydroperoxide 2 (10 g/ $\mathrm{L}$ in $\left.\mathrm{CH}_{3} \mathrm{CN}\right)$. [b] The conversion of 2 was determined by HPLC. [c] Ratio were determined by GC. [d] $\left[2\right.$ in $\left.\mathrm{CH}_{3} \mathrm{CN}\right]=20 \mathrm{~g} / \mathrm{L}$. $n d=$ not determined.

Under these conditions, the aldehydes 11 and 12 were obtained with $81 \%$ selectivity. A reaction was performed starting from about $1 \mathrm{~g}$ of hydroperoxide 2 under the optimized conditions (Scheme 2). In that case, only aldehydes were obtained with $68 \%$ GC yield. These results remain satisfying considering the high volatility of such aldehydes. Purification of the mixture by column chromatography gave nonanal $\mathbf{1 1}$ and methyl 9oxononanoate 12 with 57 and 55\% isolated yield, respectively.

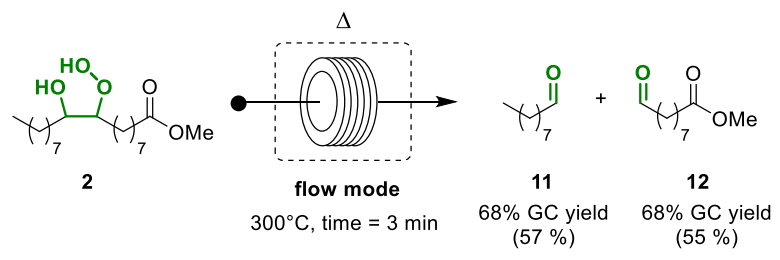

Scheme 2. Thermal cleavage of fatty $\beta$-hydroxy hydroperoxide in flow conditions. GC yield were obtained using hexadecane as an internal standard using calibration curves. Isolated yields in brakets. 
This result clearly demonstrates the feasibility of a continuous flow process to prepare aldehydes from fatty epoxides through $\beta$-hydroxy hydroperoxides and paves the way for further process development.

\section{Mechanistic considerations}

In addition to its synthetic utility for the production of aldehydes from fatty $\beta$-hydroxy hydroperoxides, this work also contributes to give some insights on the reaction mechanism for the oxidative cleavage of epoxides using $\mathrm{H}_{2} \mathrm{O}_{2}$. In a recent work, ${ }^{[20]}$ $\mathrm{Lu}$ et al. have proposed that the ring-opening of epoxide with $\mathrm{H}_{2} \mathrm{O}_{2}$ (1.2 equiv) in the presence of tungstic acid first produced the corresponding 1,2-diol and that this species is oxidized to either $\alpha$-hydroxyketone or $\beta$-hydroxy hydroperoxide. According to our work, the formation of $\beta$-hydroxy hydroperoxide through their proposed pathway seems very unlikely. In our case, the ring-opening of epoxide with aqueous $50 \% \mathrm{H}_{2} \mathrm{O}_{2}$ in the presence of tungstic acid gave $93 \%$ of $\beta$-hydroxy hydroperoxide 2 and $7 \%$ of diol 3 (see Table 1, entry 4).

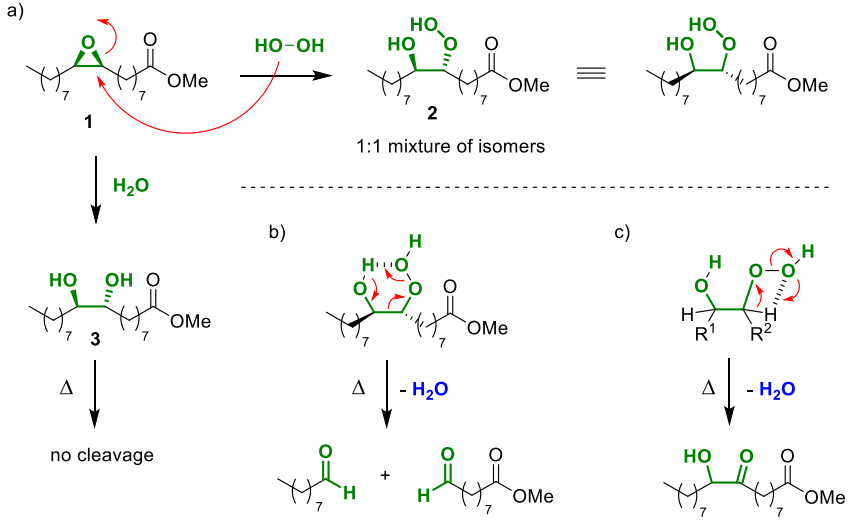

Figure 4. Mechanistic proposal for the cleavage of fatty $\beta$-hydroxy hydroperoxide to aldehydes.

This clearly demonstrates that $\mathrm{H}_{2} \mathrm{O}_{2}$ is a better nucleophile than water, ${ }^{[44]}$ if not, products 2 and $\mathbf{3}$ would have been obtained in almost equimolar ratio. So, the ring-opening of epoxide 1 with aqueous $50 \% \mathrm{H}_{2} \mathrm{O}_{2}$ mainly affords $\beta$-hydroxy hydroperoxide 2 as a $1: 1$ mixture of regioisomers (Figure $4, a)$. The formation of diol 3 results from the ring-opening of epoxide $\mathbf{1}$ with water as a competitive reaction. Noteworthy, diol 3 could not be thermally cleaved to the corresponding aldehydes under our reaction conditions. On the contrary, $\beta$-hydroxy hydroperoxide 2 could self-arrange in a six-membered transition state, in which the C-C bond could break upon heating, thus releasing the desired aldehydes and water as a co-product (Figure 4, b). Advantageously, both regioisomers afford the same aldehydes in this process. In addition, a molecule of water could be also eliminated from $\beta$-hydroxy hydroperoxide 2 to form $\alpha$ hydroxyketone $\mathbf{1 3}$ as a 1:1 mixture of regioisomers (Figure 4, c).

\section{Conclusion}

In conclusion, we have developed an original method for the cleavage of fatty epoxides to aldehydes through the formation of $\beta$-hydroxy hydroperoxide intermediates. The ring-opening of epoxidized fatty derivatives with aqueous $\mathrm{H}_{2} \mathrm{O}_{2}$ in the presence of phosphostungstic acid gave a range of fatty $\beta$-hydroxy hydroperoxides with $30-80 \%$ isolated yields (8 examples). These species were fully characterized by ${ }^{1} \mathrm{H}$ and ${ }^{13} \mathrm{C}$ NMR, HPLCHRMS and their stability was studied by DSC. The thermal cleavage of $\beta$-hydroxy hydroperoxides was first studied in batch conditions but higher selectivities towards the formation of aldehydes were obtained under flow conditions. Advantageously, the overall process does not require large excess of $\mathrm{H}_{2} \mathrm{O}_{2}$ and water was generated as the only byproduct. Finally, the fatty aldehydes obtained are excellent building-blocks for the production of bio-based additives (e.g., surfactants and hydrotropes) and monomers.

\section{Experimental Section}

Procedure for the preparation of fatty $\beta$-hydroxy hydroperoxides. In a $100-\mathrm{mL}$ double jacketed reactor, fatty epoxide derivative (1 equiv) was added in t-amyl alcohol (2M2B; $0.25 \mathrm{M}$ ), phosphotungstic acid (PTA, 0.1 mol\%) was added and then 1.1 equivalent of $\mathrm{H}_{2} \mathrm{O}_{2}(50$ wt $\%$ in water) was added dropwise. The flask was closed under argon atmosphere and magnetically stirred at $10^{\circ} \mathrm{C}$ for 16 hours (the conversion of the epoxide was followed by GC and TLC). The reaction mixture was filtered over a celite pad and washed with ethyl acetate. The filtrate was concentrated under reduced pressure to give the crude product that was purified by column chromatography (Cyclohexane/Ethyl acetate 100:0 to 60:40).

Procedure for the thermal cleavage of fatty $\beta$-hydroxy hydroperoxides to aldehydes. A solution of $\beta$-hydroxy hydroperoxide in $\mathrm{MeCN}$ was prepared with a concentration of $10 \mathrm{~g} / \mathrm{L}$. The solution was pumped through an oven heated at $300^{\circ} \mathrm{C}$ with a flow rate between 1 to 2 $\mathrm{mL} / \mathrm{min}$. The solution of aldehydes was recovered and analyzed by HPLC (for the conversion of $\beta$-hydroxy hydroperoxide) and by GC (for the yields of aldehydes). Then, the solvent was evaporated under reduced pressure. The residue was purified by column chromatography (cyclohexane / ethyl acetate: 100:0 to 80:20).

\section{Acknowledgements}

The region Auvergne Rhône-Alpes is also acknowledged for a Ph.D. grant to T.D.D.M. (Pack Ambition Recherche - project VALCOUPENZ). This project has been labeled by AXELERA, pôle de compétitivité Chimie-environnement in AuvergneRhône-Alpes. The authors also thank the SAS PIVERT for a Ph.D. grant to N.D.V. (GENESYS program - project WP3P21 Bioaldehydes). This work was performed in partnership with the SAS PIVERT, within the frame of the French Institute for the Energy Transition (Institut pour la Transition Energétique (ITE) P. I. V. E. R. T. (http://www.institut-pivert.com)) selected as an Investment for the Future ("Investissements d'Avenir"). This work was supported, as part of the Investments for the Future, by the French Government under the reference ANR-001-01. L. Joucla (LHCEP, Lyon) is also acknowledged for preliminary safety tests on $\beta$-hydroxy hydroperoxides. The "Centre Commun de 
Spectrométrie de Masse" of Lyon (E. Fromentin, A. Vauchez, C. Duchamp) is thanked for HPLC-MS analyses.

Keywords: Aldehydes • Epoxides $~ \beta$-Hydroxy hydroperoxides • Thermal cleavage $\bullet$ Flow chemistry

[1] B. A. Murray, "Reaction of aldehydes and ketones and their derivatives" in Organic Reaction Mechanisms, 2016, pp. 1-70.

[2] a) A. Corma, S. Iborra, A. Velty, Chem. Rev. 2007, 107, 2411-2502; b) P. Gallezot, Chem. Soc. Rev. 2012, 41, 1538-1558; c) M. Besson, P. Gallezot, C. Pinel, Chem. Rev. 2014, 114, 1827-1870; d) R. A. Sheldon, Green Chem. 2014, 16,950-963.

[3] a) R. Mariscal, P. Maireles-Torres, M. Ojeda, I. Sádaba, M. López Granados, Energy Environ. Sci. 2016, 1144-1189; b) X. Li, P. Jia, T. Wang, ACS Catal. 2016, 6, 7621-7640; c) Y. Luo, Z. Li, X. Li, X. Liu, J. Fan, J. H. Clark, C. Hu, Catalysis Today 2019, 319, 14-24.

[4] a) J. Lewkowski, ARKIVOC, 2001, i 17-54; b) R.-J. van Putten, J. C. van der Waal, E. de Jong, C. B. Rasrendra, H. J. Heeres, J. G. de Vries, Chem. Rev. 2013, 113, 1499-1597; c) R. Karinen, K. Vilonen, M. Niemelä, ChemSusChem 2011, 4, 1002-1016; d) A. A. Rosatella, S. P. Simeonov, R. F. M. Frade, C. A. M. Afonso, Green Chem. 2011, 13 754-793; e) X. Kong, Y. Zhu, Z. Fang, J. A. Kozinski, I. S. Butler, L. Xu, H. Song, X. Wei, Green Chem. 2018, 20, 3657-3682; f) L. Hu, A. He, X Liu, J. Xia, J. Xu, S. Zhou, J. Xu, ACS Sustainable Chem. Eng. 2018, 6, $15915-15935$

[5] a) Z. Zhang, G. W. Huber, Chem. Soc. Rev. 2018, 47, 1351-1390; b) P. Pal, S. Saravanamurugan, ChemSusChem 2019, 12, 145-163.

[6] a) M. Fache, E. Darroman, V. Besse, R. Auvergne, S. Caillol, B. Boutevin, Green Chem. 2014, 16, 1987-1998; b) M. Fache, B. Boutevin S. Caillol, Eur. Polym. J. 2015, 68, 488-502; c) M. Fache, B. Boutevin, S. Caillol, ACS Sustainable Chem. Eng. 2016, 4, 35-46.

[7] a) U. Biermann, W. Friedt, S. Lang, W. Lìns, G. Machmiller, J. O. Metzger, M. Rìsch gen. Klaas, H. J. Sch.fer, M. P. Schneider, Angew. Chem. Int. Ed. 2000, 39, 2206-2224; Angew. Chem. 2000, 112, 22922310; b) U. Biermann, U. Bornscheuer, M. A. R. Meier, J. O. Metzger, H. J. Schäfer, Angew. Chem. Int. Ed. 2011, 50, 3854-3871; Angew. Chem. 2011, 123, 3938-3956; c) M. A. R. Meier, J. O. Metzger, U. S. Schubert, Chem. Soc. Rev. 2007, 36, 1788-1802; d) Y. Xia, R. C Larock, Green Chem. 2010, 12, 1893-1909; e) J. M. Fraile, J. I. García C. I. Herrerías, E. Pires, Synthesis, 2017, 49, 1444-1460.

[8] C. Kohlpaintner, M. Schulte, J. Falbe, P. Lappe, J. Weber. "Aldehydes, Aliphatic" in Ullmann's Encyclopedia of Industrial Chemistry. Weinheim Wiley-VCH, 2013.

[9] For a review about hydroformylation of oleochemicals, see: T. Vanbésien, E. Monflier, F. Hapiot, Eur. J. Lipid Sci. Technol. 2016, 118, 26-35.

[10] For our contribution on the reductive alkylation of polyols with aldehydes, see: a) Y. Shi, W. Dayoub, A. Favre-Réguillon, G.-R. Chen, M. Lemaire, Tetrahedron Lett, 2009, 50, 6891-6893; b) Y. Shi, W. Dayoub, G.-R. Chen, M. Lemaire, Green Chem. 2010, 12, 2189-2195; c) C. Gozlan, R. Lafon, N. Duguet, A. Redl, M. Lemaire, RSC Adv. 2014, 4, 50653-50661; d) Sutter, M.; Da Silva, E.; Duguet, N.; Raoul, Y.; Métay, E.; Lemaire, M. Chem. Rev. 2015, 115, 8609-8651; e) Gozlan, C.; Deruer, E.; Duclos, M.-C.; Molinier, V.; Aubry, J.-M.; Redl, A.; Duguet, N.; Lemaire, M. Green Chem. 2016, 18, 1994-2004; f) Belmessieri, D.; Gozlan, C.; Duclos, M.-C.; Molinier, V.; Aubry, J.-M.; Dumitrescu, O.; Lina, G.; Redl, A.; Duguet, N.; Lemaire, M. Eur. J. Med. Chem. 2017, 128, 98-106; g) Belmessieri, D.; Gozlan, C.; Duclos, M. C.; Dumitrescu, O.; Lina, G.; Redl, A.; Duguet, N.; Lemaire, M. Bioorg. Med. Chem. Lett. 2017, 27, 4660-4663.

[11] a) B.-J. Kollbe Ahn, S. Kraftb, X. S. Sun, J. Mater. Chem. 2011, 21 9498; b) M. Dierker, H. J. Schäfer, Eur. J. Lipid Sci. Technol. 2010, 112 $122-136$.

[12] a) D. L. Sparks, L. Antonio Estévez, R. Hernandez, Green Chem. 2009, 11, 986; b) S. E. Dapurkar, H. Kawanami, T. Yokoyama, Y. Ikushima Top. Catal. 2009, 52, 707-713; c) B. R. Travis, R. S. Narayan, B. Borhan, J. Am. Chem. Soc. 2002, 124, 3824-3825.
[13] a) G. Maerker, E. T. Haeberer, U.S. Patent, US 3405149, 1968; b) S. Mithran, A. S. Subbaraman, Molecules, 1999, 4, 159-164.

[14] a) K. Louis, L. Vivier, J.-M. Clacens, M. Brandhorst, J.-L. Dubois, K. De Oliveira Vigier, Y. Pouilloux, Green Chem. 2014, 16, 96-101; b) T. S Omonov, E. Kharraz, P. Foleyb, J. M. Curtis, RSC Adv. 2014, 4, 53617-53627; c) M. D. Lundin, A. M. Danby, G. R. Akien, T. P. Binder D. H. Busch, B. Subramaniam, ACS Sustainable Chem. Eng. 2015, 3, $3307-3314$.

[15] N. D. Vu, B. Guicheret, N. Duguet, E. Metay, M. Lemaire, Green Chem. 2017, 19, 3390-3399.

[16] a) E. Deruer, N. Duguet, M. Lemaire, ChemSusChem 2015, 8, 24812486 ; b) N. D. Vu, S. Bah, E. Deruer, N. Duguet, M. Lemaire, Chem. Eur. J. 2018, 24, 8141-8150.

[17] N. D. Spiccia, E. Border, J. Illesinghe, W. R. Jackson, A. J. Robinson, Synthesis 2013, 45, 1683-1688.

[18] M. Lu, L. Peng, Q. Xie, N. Yang, H. Jin, Z. Wu, Y. Nie, X. Liu, X. Lu, J. Ji, Green Chem. 2019, 21, 560-566.

[19] M. Lu, L. Peng, Q. Xie, Y. Nie, X. Liu, X. Lu, J. Ji, Eur. J. Lipid Sci. Technol. 2018, 120, 1700415.

[20] L. Peng, Q. Xie, Y. Nie, X. Liu, M. Lu, J. Ji, RSC Adv. 2019, 9, 2306123070.

[21] Reporting GC yields is common practice in catalysis. However, in that specific case that is the cleavage of epoxides using $\mathrm{H}_{2} \mathrm{O}_{2}$, it may be not satisfactory. In the present study, we have clearly demonstrated that $\beta$-hydroxy hydroperoxides are formed as intermediates under mild conditions. If GC is only used to determine the yield of aldehydes without checking the full conversion of $\beta$-hydroxy hydroperoxide intermediates (e.g., by NMR or HPLC), it is completely misguiding because $\beta$-hydroxy hydroperoxides readily decomposed in the GC injector to form the desired aldehydes during the analysis. Consequently, the isolation of aldehydes is of prime importance.

[22] N. D. Vu, Ph.D. thesis, Université Claude Bernard Lyon 1, defended 2018/11/19

[23] For early reports, see: a) G. B. Payne, C. W. Smith, J. Org. Chem 1957, 22, 1682-1685; b) A. M. Mattucci, E. Perrotti, A. Santambrogio, Chem. Commun. 1970, 1198-1199.

[24] The reaction was first reported uncatalyzed using $98 \% \mathrm{H}_{2} \mathrm{O}_{2}$, see: W Adam, A. Rios, Chem. Commun. 1971, 822-823.

[25] V. Subramanyam, C. L. Brizuela, A. H. Soloway, J. Chem. Soc., Chem Commun. 1976, 508-509.

[26] Y. Ogata, Y. Sawaki, H. Shimizu, J. Org. Chem. 1978, 43, 1760-1763.

[27] X. Yan, C. Qiao, Z. Guo, Synlett 2013, 24, 502-506.

[28] Y.-H. Liu, Z.-H Zhang, T.-S. Li, Synthesis 2008, 20, 3314-3318.

[29] Y. Li, H.-D. Hao, Y. Wu, Org. Lett. 2009, 11, 2691-2694.

[30] P.-H. Li, B.-L. Li, Z.-M. An, L.-P. Mo, Z.-S. Cui, Z.-H. Zhang, Adv. Synth Catal. 2013, 355, 2952-2959.

[31] Y.-H. Liu, H.-C. Hu, Z.-C. Ma, Y.-F. Dong, C. Wang, Y.-M. Pang, Monatsh Chem. 2018, 149, 551-556.

[32] I. Shinichiro, N. Sunao, N. Takuji, K. Hiroko, Jpn. Kokai Tokkyo Koho 2003342255.

[33] V. Benessere, M. E. Cucciolito, A. D. Santis, M. D. Serio, R. Esposito, F. Ruffo, R. Turco, J. Am. Oil Chem. Soc. 2015, 92, 1701-1707.

[34] Better results could probably be obtained using a more concentrated aqueous solution of $\mathrm{H}_{2} \mathrm{O}_{2}$ or ethereal $\mathrm{H}_{2} \mathrm{O}_{2}$ but no attempt was made for safety reasons.

[35] Similar conditions were reported in a patent that was published during the finalization of the present article: C. Bordier, V. Escande, F. Caijot, C. Darcel, WO2020/169932. However, the deposit date of this patent occurred well after the first communication of the present study, see reference 22.

[36] a) G. Payne, C. W. Smith, J. Org. Chem. 1957, 22, 1682-1685; b) W. Adam, A. J. Rios, Chem. Soc., Chem. Commun. 1971, 822; c) V. Subramanyam, C. L. Brizuela, A. H. Soloway, J. Chem. Soc. Chem. Commun. 1976, 508-509.

[37] a) W. Richardson, T. C. Heesen, J. Org. Chem. 1972, 37, 3416-3419; b) Y. Ogata, Y. Sawaki, H. Shimizu, J. Org. Chem. 1978, 43, 17601763.

[38] X. Gu, W. Zhang, R. G. Salomon, J. Org. Chem. 2012, 77, 1554-1559. 
[39] E. Antonelli, R. D’Aloisio, M. Gambaro, T. Fiorani, C. Venturello, J. Org. Chem. 1998, 63, 7190-7206.

[40] F. Cataldo, Chem. Phys. Lipids 2013, 175-176, 41-49.

[41] a) F. Cataldo, Tetrahedron Lett. 2015, 56, 994-998; b) F. Cataldo, Ozone: Sci. Eng. 2015, 37, 431-440.

[42] S. Alazet, J. Preindl, R. Simonet-Davin, S. Nicolai, A. Nanchen, T. Meyer, and J. Waser, J. Org. Chem. 2018, 19, 12334-12356.

[43] The set-up for the cleavage of $\beta$-hydroxy hydroperoxide is described in the Supporting Information.

[44] E. G. Sander, W. P. Jencks, J. Am. Chem. Soc. 1968, 90, 6154-6162. 


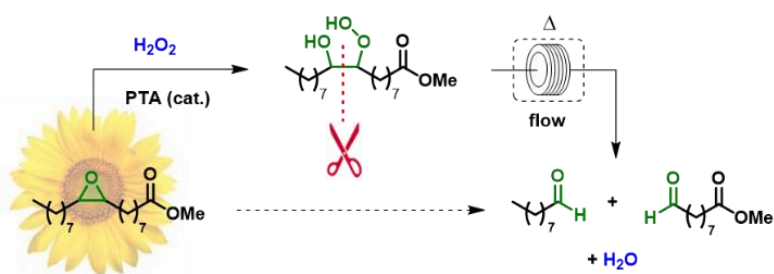

Biobased aldehydes were prepared from fatty epoxides through thermal cleavage of $\beta$-hydroxy hydroperoxide species. 